\title{
Capítulo II - As dimensões da ideologia a partir da leitura Gramsciana de Marx
}

\author{
Anita Helena Schlesener
}

\section{SciELO Books / SciELO Livros / SciELO Libros}

SCHLESENER, AH. As dimensões da ideologia a partir da leitura Gramsciana de Marx. In: Grilhões invisíveis: as dimensões da ideologia, as condições de subalternidade e a educação em Gramsci [online]. Ponta Grossa: Editora UEPG, 2016, pp. 65-92. ISBN 978-85-7798-234-9. Available from: doi: $10.7476 / 9788577982349.0003$. Also available in ePUB from: http://books.scielo.org/id/y3zhj/epub/Schlesener-9788577982349.epub.

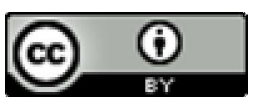

All the contents of this work, except where otherwise noted, is licensed under a Creative Commons Attribution $\underline{4.0 \text { International license. }}$

Todo o conteúdo deste trabalho, exceto quando houver ressalva, é publicado sob a licença Creative Commons Atribição 4.0.

Todo el contenido de esta obra, excepto donde se indique lo contrario, está bajo licencia de la licencia Creative Commons Reconocimento 4.0 . 


\section{CAPÍTULO II}

\section{As dimensões DA IDEOLOGIA A PARTIR DA LEITURA GRAMSCIANA DE MARX}

O conteúdo da consciência encontra a sua origem e explicação no conteúdo da situação histórica (CHATELET, 1972, p. 231).

A questão da ideologia, temática que nos propomos abordar neste capítulo, nos desafia por sua amplitude e por ter sido tratada de diversas perspectivas ao longo das últimas décadas. A ela se vincula o título deste livro, que visa a mostrar a dimensão que a ideologia toma na vida dos homens na sociedade capitalista. Nos Cadernos do Cárcere, Gramsci se refere ao tema em 35 fragmentos ao longo de sua obra, iniciando com a origem do conceito na filosofia francesa, passando por uma reinterpretação da noção marxiana de ideologia para, enfim, explicitar o conceito na sua crítica aos pensamentos de Croce e de Bukharin. Entre os comentadores de Gramsci que abordam o assunto cabe citar o detalhado levantamento de Guido Liguori no léxico Le Parole di Gramsci, as pesquisas de Fabio Frosini em torno das continuidades e rupturas entre Marx e Gramsci, além de Giuseppe Prestipino no livro Tradire Gramsci e as publicações sobre a crítica, por um lado a Croce e por outro a Bukharin, que abordamos em outros escritos ${ }^{1}$. O recorte que nos propomos é a partir da abordagem e releitura gramsciana de Marx na definição de ideologia, a fim de explicitar sua relação com as noções de hegemonia e de linguagem, presentes nos Cadernos.

A formação do imaginário social e seus desdobramentos na política, explicitada por Marx ao longo de sua obra nas reflexões sobre ideologia, são o pressuposto do pensamento de Gramsci sobre a sua conceituação. Gramsci provavelmente não teve acesso à A Ideologia Alemã, publicada somente em $1932^{2}$, o que se depreende de sua leitura, concentrada nos textos que tinha em mãos.

1 A crítica a Bukharin se encontra em artigos apresentados em eventos (CEMARX e outros) e no livro (SCHLESENER, 2005); a leitura de Croce foi apresentada em artigos publicados na Revista Unisinos (São Leopoldo, 2007), Revista Reflexão (Campinas, 2006), Revista Sociedade e Estado (Brasília, 2007). 2 Conforme Guido Liguori, Gramsci talvez tenha tomado conhecimento da primeira parte do livro, Feuerbach, publicada em 1924, em russo e, posteriormente, em 1926, em alemão. Como não se encontram citações ou referências a esse texto nos escritos de Gramsci, ele "provavelmente não teve a disposição 
A Ideologia Alemã, como os próprios autores assinalam, tem a finalidade de um acerto de contas com a tradição filosófica a partir do debate com os herdeiros da filosofia hegeliana, no questionamento do pensamento de Feuerbach, Stirner e os irmãos Bauer, bem como no confronto indireto com o pensamento de Hegel, seguindo a senda aberta nos Manuscritos econômico-filosóficos, de Marx. Nos Manuscritos, porém, o acento se coloca nas noções de trabalho e de alienação, enquanto A ideologia Alemã explicita as condições históricas de produção e reprodução da consciência como parte do processo contraditório de produção e reprodução da vida material.

De uma perspectiva ampla, nos escritos de Marx, as raízes da noção de ideologia estão no modo como se instituem as relações de trabalho e as relações sociais, podendo ser encontrada desde os Manuscritos Econômicofilosóficos, até a sua obra mais completa no primeiro livro de O Capital, na explicitação da noção de mercadoria, na estrutura do modo de produção capitalista, a partir da análise do modo como se organizam as relações de trabalho e se produzem os valores (de uso e de troca).

Conforme Chatelet (2004, p. 108-109), Marx acentuou três características da ideologia ao longo de seu trabalho: a "ideologia é alienante, mistificante e reificante". Alienante porque "impõe ao homem uma visão da realidade que o torna estranho à sua verdadeira prática social”; mistificante ou mitificante porque ela produz "um certo número de mitos, destinados a polarizar a afetividade social"; e é ainda reificante porque "tende a fazer durar o estado de coisas dadas", ou seja, efetua uma operação de legitimação do dado, procurando "provar que o estado de coisas corresponde à natureza, à vocação, ao destino da humanidade e que este estado de coisas realiza plenamente o que sempre se desejou”. Estas dimensões da ideologia se ampliam na sociedade contemporânea a partir dos mecanismos tecnológicos inseridos tanto no modo de produção quanto na vida social, alterando a noção de verdade, enrijecendo o pensamento e obscurecendo a nossa visão de mundo.

Na perspectiva dos escritos se Marx, os Manuscritos Econômicofilosóficos trazem as primeiras intuições de Marx sobre a estrutura do modo de produção capitalista, a partir da análise das formas históricas de organização do trabalho e apropriação da força de trabalho por meio da consolidação da propriedade privada dos meios de produção; delineando essa estrutura, Marx explicita as várias formas de estranhamento/alienação

aquele que hoje estamos habituados a considerar o lugar de nascimento do moderno conceito de ideologia na sua conotação negativa marxiana e marxista" (FROSNI e LIGUORI, 2007, p. 132). 
que se produzem no contexto das relações de trabalho. Definido basicamente como um conjunto de ações pelas quais o produtor não se reconhece no produto do seu trabalho, o estranhamento estende-se a toda a vida individual e social: o homem torna-se estranho ao resultado de sua atividade, que lhe aparece como exterior, estranho ou distante da natureza, isolado dos outros e estranho a si próprio.

Esse movimento já traz implícita uma noção de ideologia, embora não se aborde ainda explicitamente o conceito: evidencia-se no processo de alienação uma inversão de valores que altera toda a significação da vida humana, na medida em que ocorre o movimento de objetivação valoriza-se o mundo das coisas e se desvaloriza o humano. Esse processo que ocorre no âmbito das relações econômicas e sociais, desdobra-se no modo de pensar e entender a realidade natural e o conjunto das relações sociais.

Tal como a propriedade privada é apenas a expressão sensível do fato de que o homem se torna objetivo para si e, ao mesmo tempo, se converte em um objeto estranho e inumano, do fato de que a exteriorização de sua vida é a alienação da sua vida e sua efetivação sua desefetivação, uma efetividade estranha, a superação positiva da propriedade privada, isto é, a apropriação sensível pelo homem e para o homem da essência e da vida humanas, do homem objetivo, das obras humanas, não deve ser concebida só no sentido do gozo imediato, exclusivo, no sentido da posse, do ter (MARX, 1974, p. 16-7).

A inversão aqui se apresenta na perda da dimensão global da vida humana, do homem como um ser que se produz e se conhece enquanto ser social, tanto que suas relações consigo mesmo, com o mundo das coisas e com os outros, "ver, ouvir, cheirar, saborear, sentir, pensar, observar, perceber, querer, atuar, amar - em resumo, todos os órgãos de sua individualidade", enquanto "órgãos que são imediatamente coletivos em sua forma" são, em seu comportamento objetivo, a apropriação desse movimento de produção do ser social. Porém, o que aparece imediatamente, enquanto efetivação imediata, é o ter individual, possessivo: a "propriedade privada tornou-nos tão estúpidos e unilaterais que um objeto só é nosso quando o temos, quando existe para nós como capital ou quando é imediatamente [...] utilizado por nós" (MARX, 1974, p. 17). Essa inversão se expressa ainda na maneira de entender a sensibilidade como individual e isolada, quando os sentidos, de modo geral, também se transformam com o movimento da história, pois a percepção sensível resulta de uma formação e inserção social.

Conforme a leitura de Ranieri (2000, p. 20-21), existe uma continuidade entre os Manuscritos de Paris e A Ideologia Alemã, de modo a se 
evidenciar, nos Manuscritos, a "exposição geral de um sistema" nascente que, em A Ideologia Alemã, toma forma mais acabada na crítica "às elaborações de Hegel e seus discípulos, além de estabelecer as bases orgânicas de uma teoria materialista da história". O elo se evidencia no modo como $A$ Ideologia Alemã retoma e amplia os quatro momentos de formação da alienação a partir da divisão do trabalho, da propriedade privada e das relações de troca no contexto da concentração dos meios de produção. Fundado na produção e consumo de mercadorias, o modo de produção capitalista tem como pressuposto a concentração dos meios de produção e a exploração da força de trabalho, a partir dos quais se desenrola o processo vital por meio do qual se constrói a sociedade e se elaboram as representações do social.

Os Manuscritos nos mostram que a representação de si e do mundo no contexto da filosofia hegeliana supõe a alienação, que o pensar abstrato é aquele que separa sujeito e objeto como elementos estanques que se opõe, o que se depreende da crítica ao pensamento de Hegel, a partir do qual o "homem alienado de si mesmo é também o pensador alienado de sua essência, isto é, da essência natural e humana”, cujos limites não consegue superar porque permanece no campo da abstração e da contemplação (MARX, 1974, p. 53), desvinculadas do contexto concreto do trabalho. Ao trabalhador, sem a dimensão social de sua produção, resta apenas a ação enquanto reposição da força de trabalho, a luta pela sobrevivência cotidiana.

Os Manuscritos prenunciam a sistematização mais elaborada, concretizada em $O$ Capital, na análise dos mistérios que a mercadoria oculta. Um mistério "ao mesmo tempo perceptível e impalpável”, que provém de sua própria forma ou da forma geral do valor que quantifica e torna equivalentes os trabalhos humanos nela embutidos; as mercadorias são pressupostas como iguais, a partir de uma série de abstrações necessárias para concretizar as relações de troca (MARX, 1980, p.79-80).

A mercadoria é misteriosa simplesmente por encobrir as características sociais do próprio trabalho dos homens, apresentando-as como características materiais e propriedades sociais inerentes aos produtos do trabalho; por ocultar, portanto, a relação social entre os trabalhos individuais dos produtores e o trabalho total, ao refletí-la como relação social existente, à margem deles, entre os produtos do seu próprio trabalho (MARX, 1980, p. 80).

Esse ocultamento dos elementos sociais do trabalho, ou seja, do modo como os homens se organizam, na produção e reprodução de sua vida material articulando suas atividades produtivas, do modo como transformam 
a natureza dispendendo suas forças fisiológicas e criando as formas de sociabilidade, não aparecem ou não são considerados no processo de quantificação do trabalho para fins intercambiáveis, fator que caracteriza uma abstração necessária para viabilizar as formas de troca. Por meio desse ocultamento "os produtos do trabalho se transformam em mercadorias, coisas sociais, com propriedades perceptíveis e imperceptíveis aos sentidos" (MARX, 1980, p. 81).

Na medida em que isso acontece ocorre uma inversão de perspectiva, que faz com que a "igualdade dos trabalhos humanos fique disfarçada sob a forma da igualdade dos produtos do trabalho como valores"; segue-se que a "medida, por meio da duração, do dispêndio da força humana de trabalho toma a forma de quantidade de valor dos produtos do trabalho"; nesse movimento, "as relações entre os produtores, nas quais se afirma o caráter social dos seus trabalhos, assumem a forma de relação social entre os produtos do trabalho" (MARX, 1980, p. 80).

Essa inversão se constitui, na aparência imediata dos sujeitos, na separação entre qualidade e quantidade, sujeito e objeto e "na medida em que o costume fixa essas proporções, parecem elas derivar da natureza dos produtos do trabalho" (MARX, 1980, p. 83). O aprofundamento das formas de abstração que possibilitam intercambiar os produtos do trabalho a partir da determinação de quantidades de valor permite a Marx mostrar que a raiz da auto-alienação dos homens (e da ideologia) se encontra no modo como se organizam as relações de trabalho e as relações de troca, a partir da constituição da forma mercadoria. A aparência imediata da atividade social como relação entre coisas que assumem independência em relação aos sujeitos do trabalho se desdobra na representação de si e do mundo; assim, por exemplo, a linguagem, um produto social dos homens, criada a partir de necessidades coletivas, aparece como a essência individual pela qual o homem se diferencia do restante da natureza.

Em síntese, ao desvendar o mistério da mercadoria e o seu caráter de fetiche, Marx explicita tanto o funcionamento do modo de produção capitalista em sua estrutura econômica e social quanto as relações ideológicas que a sustentam, ou seja, a vinculação interna entre o trabalho, a divisão social do trabalho e o modo de vida social, que se traduz em um modo de pensar, de sentir e de ver o mundo. A ideologia se expressa na inversão do imaginário no qual "uma relação social definida, estabelecida entre os homens, assume a forma fantasmagórica de uma relação entre coisas”. 
Esse fenômeno se denomina fetichismo, algo inseparável da produção de mercadorias (MARX, 1980, p. 81).

$\mathrm{O}$ enigma a decifrar se encontra no fato que os homens "fazem isto sem o saber" (MARX, 1980, p. 82), ou seja, tomam a aparência por realidade, a mercadoria como coisa independente do conjunto do trabalho social, exterior e estranha, passando a entender seu próprio trabalho como algo independente, objetivo, parte do mundo das coisas, força de trabalho submetida a leis externas e que lhe são estranhas. Daí decorre entender a linguagem como essência do humano e o passado histórico como constituído de fatos objetivos e estáticos no tempo, podendo ser retomados como de fato ocorreram. A mesma lógica instrumental que estrutura as relações econômicas e sociais, sedimenta-se no senso comum enquanto um conhecimento imediato, fragmentado e naturalizado, tomado como universal e verdadeiro.

Desvendar o segredo oculto da mercadoria na "determinação da quantidade do valor do tempo do trabalho" permite explicitar as formas da vida humana e "seguir a rota oposta à do seu verdadeiro desenvolvimento histórico”, ou seja, a história não pode ser lida linearmente, mas lida a partir "do fato consumado, quando estão concluídos os resultados do processo de desenvolvimento" (como Marx faz com a noção de mercadoria). E o "fato consumado" pode ser a visão invertida do real, porque oculta as múltiplas determinações que atuaram para a sua formulação (MARX, 1980, p. 84). $O$ Capital não é apenas um livro sobre economia política, mas uma obra filosófica que articula econômico, social, político e ideológico e o modo como estas instâncias se determinam reciprocamente formando uma nova teoria da história, como o coroamento de toda a produção teórica de Marx.

Essa breve incursão sobre o fetichismo da mercadoria pretendeu mostrar como Marx construiu a sua noção de ideologia a partir das categorias da economia burguesa no contexto de uma nova teoria da história que, a partir da explicitação do conjunto de relações econômicas, sociais, políticas e ideológicas, visa a transformar radicalmente a "estrutura do processo vital da sociedade" desvelando o "véu nebuloso e místico" que a encobre para criar uma nova ordem social e política (Marx, 1980, p. 88).

\section{Notas sobre ideologia a partir de A Ideologia Alemã}

Não é o esqueleto (em sentido restrito) que nos faz enamorar de uma mulher, mas compreende-se quanto o esqueleto contribui para a graça dos movimentos (Q. 1O, p. 1321). 
A breve abordagem que nos propomos aqui visa a mostrar, primeiro, que é a partir do empírico, mas não do imediatamente dado e sim do conjunto de relações nas quais os homens produzem e reproduzem a sua vida, que se forma a consciência; segundo, que este movimento de produção da vida tem um caráter eminentemente educativo que se traduz tanto nas normas de sociabilidade quanto no modo de ser e de pensar dos sujeitos. A metáfora em epígrafe visa a lembrar o modo como Marx, em O Capital, desvela o que se esconde sob a aparência social e o imediatamente dado, a fim de explicitar a estrutura vital da sociedade, compreendendo o "valor concreto (histórico) das superestruturas na filosofia da praxis" (Q. 10, p. 1321).

O ponto de partida de A Ideologia Alemã é, como acentuamos acima, a tradição filosófica hegeliana, nas leituras de Feuerbach e dos irmãos Bruno e Stirner, para mostrar que se esqueceram de "perguntar qual seria a relação entre a filosofia alemã e a realidade alemã", ou seja, a "relação entre a sua crítica e o seu próprio meio material” (MARX, 1976, p. 17). Esse "meio material” torna-se o objeto de análise de Marx, a fim de explicitar os limites da crítica dos filósofos hegelianos: as nossas premissas, diz Marx, "não são arbitrárias, nem dogmas"; são bases empíricas concretas: os "indivíduos reais, a sua ação e as suas condições materiais de existência”, tanto as históricas quanto as que eles próprios criam cotidianamente (MARX, 1976, p. 18).

Em seguida, pontua as condições de produção desses meios, que dependem em primeiro lugar da natureza, com a qual os homens estabelecem um modo determinado de atividade que transforma a natureza ao mesmo tempo em que os transforma e os define enquanto homens: a essência ou o modo de ser dos indivíduos "depende das condições materiais de sua produção", condicionando tanto a sua formação social quanto todo o seu desenvolvimento sensível e intelectual individual.

A base material ou pressuposto para se definir o que é o homem é o trabalho e a divisão social do trabalho, cujo desenvolvimento e graduação se traduz na separação entre os trabalhos específicos, entre cidade e campo, entre trabalho manual e trabalho intelectual, que modela a estrutura social e política. Aos momentos e à complexificação da divisão social do trabalho "correspondem formas diferentes de propriedade", assim como novas "relações entre os indivíduos no que toca à matéria, aos instrumentos e aos produtos do trabalho" (MARX, 1976, p. 20).

Na sequência, Marx (1976, p. 24) pontua as formas de propriedade que surgiram até a instituição da propriedade privada moderna e a sua 
consolidação na propriedade privada dos meios de produção. Tem-se então "sempre indivíduos determinados" em "relações de produção determinadas" a partir das quais "entram em relações sociais e políticas determinadas", dados gerados pela "observação empírica".

É desse contexto que se produzem as concepções de mundo, as ideias, forma-se a consciência: as "representações, o pensamento, o comércio intelectual dos homens surge aqui como emanação direta do seu comportamento material”. A produção das representações é, portanto, condicionada "por um determinado desenvolvimento das forças produtivas e do modo de relações que lhe corresponde", ou seja, o homem "é o seu processo da vida real" (MARX, 1976, p. 25).

A partir desse momento, Marx (1976, p. 25-26) inicia a explicitação do que significa a ideologia, inicialmente definida como a inversão do que seja o homem e suas relações, comparando o processo com a imagem invertida de uma câmara escura, que nos recorda o processo físico de produção da visão.

A consciência é um produto social, é fruto de uma determinada forma de relação do indivíduo com os outros, mas aparece como individual e separada do entorno. A base desse processo está na divisão social do trabalho, que gera as condições para que a consciência se emancipe do real existente e se proponha como puro pensamento, teoria "pura" que formula leis, "teologia, filosofia, moral, etc.” (MARX, 1976, p. 37). O filósofo (Feuerbach e companhia), assim como o homem comum,

não vê que o mundo sensível em seu redor não é objeto dado diretamente para toda a eternidade, e sempre igual a si mesmo, mas antes o produto da indústria e do estado da sociedade, isto é, um produto histórico, o resultado da atividade de toda uma série de gerações cada uma das quais ultrapassava a precedente, aperfeiçoando a sua indústria e o seu comércio, e modificava o seu regime social em função da modificação das necessidades (MARX, 1976, p. 30).

A partir da divisão social do trabalho se explicita o modo como se constitui a alienação: verificando-se a separação entre trabalho manual e trabalho intelectual, assim como a cisão entre interesse particular e interesse comum a partir da instituição da propriedade privada, a atividade passa a ser "dividida não mais voluntariamente", cada indivíduo passa a ter "uma esfera de atividade exclusiva que lhe é imposta e da qual não pode sair", para não perder os meios de subsistência; nesse contexto, "a ação do homem transforma-se para ele num poder estranho que se lhe opõe e o subjuga, em vez de ser ele a dominá-la” (MARX, 1976, p. 40-41). O trabalho deixa de ser 
meio de realização do homem como indivíduo completo e toda a vida fica reduzida a produzir os meios de sobrevivência.

Chega-se a um momento em que o trabalhador precisa enfrentar-se com dois fatos precisos: a objetivação das forças produtivas, que "já não são para os indivíduos as suas próprias forças, mas as da propriedade privada”; a conversão de cada um em indivíduo abstrato, sendo o trabalho, o "único laço que os une ainda às forças produtivas e à sua própria existência”; o trabalho "perdeu para eles toda a aparência de manifestação de si e só lhes conserva a vida definhando-a" (MARX, 1976, p. 91).

Esta redução que caracteriza a alienação é também lida como inversão ideológica, na constatação que "manifestação de si e produção da vida material estão de tal modo separadas que a vida material é considerada como fim e a produção da vida material", ou seja, o "trabalho, como meio (agora a única forma possível, embora negativa, da manifestação de si)" (MARX, 1976, p. 91-92).

Na medida em que a teoria se emancipa da realidade efetiva, a ideologia assume a função de ocultar esse conjunto estrutural na forma de teoria da história: a visão parcial dos dominantes assume a dimensão universal de verdade objetiva. A condição para manter-se no poder é "representar o seu interesse como sendo interesse comum", dando-lhes a "forma da universalidade", a fim de gerar a crença de que tais interesses sejam os “únicos razoáveis, os únicos verdadeiramente válidos”. Marx afirma aqui o que se expressa mais adiante no Manifesto do Partido Comunista, publicado juntamente com Engels: os "pensamentos da classe dominante são também, em todas as épocas, os pensamentos dominantes". A “classe que dispõe dos meios de produção material dispõe igualmente dos meios de produção intelectual”, para a sua conservação e domínio (MARX, ENGELS, 1978, p. 55-56).

O pensamento dos subalternos, que "não possuem os meios de produção intelectual” está igualmente "submetido à classe dominante”. Desse modo, a "existência de ideias revolucionárias numa época determinada pressupõe já a existência de uma classe revolucionária” (MARX, ENGELS, 1978 , p. 57). Tanto uma quanto a outra se produzem no movimento contraditório de fusão e cisão entre grupos e tendências que compõe as partes conflitantes em presença. Ao se defrontar com os grupos dominantes, a classe revolucionária aparece "não como classe mas como representante da sociedade inteira”, ou como representante dos interesses de todos os 
subalternos. É no movimento de luta e organização política que se definem as posições efetivas de classe, assim como a função dos intelectuais, que acabam dando a direção da história, sendo os "fabricantes da história", como os dominadores (MARX, ENGELS, 1978, p. 58-9).

Por tudo o que se acentuou, tem-se a assertiva de Marx em Para a crítica da Economia Política, segundo a qual as "formas ideológicas pelas quais os homens tomam consciência" de si e do mundo tem como base as condições econômicas de produção e a formação social, de modo que: "assim como não se julga o que um indivíduo é a partir do julgamento que ele faz de si mesmo", assim também "não se pode julgar uma época de transformação a partir de sua própria consciência"; para entender realmente o movimento histórico, "é preciso explicar esta consciência a partir das contradições da vida material, a partir do conflito existente entre as forças produtivas sociais e as relações de produção" (MARX, 1974c, p. 136).

No dizer de Guido Liguori (2007, p. 132-133), essa conotação negativa da ideologia expressa na primeira parte de $A$ Ideologia Alemã provavelmente era desconhecida para Gramsci, mas teve acesso a alguns elementos dela, na leitura do Prefácio de 1859 e de uma carta de Engels endereçada a Franz Mehring, datada de 14/07/1893, amplamente divulgada e que define ideologia como "falsa consciência". Gramsci provavelmente parte da combinação do Prefácio de 1859 com o escrito de Engels, para elaborar o seu conceito positivo de ideologia, como se apresenta nos Cadernos do Cárcere.

\section{A noção gramsciana de ideologia}

Se a crítica da ideologia se propõe a examinar os fundamentos sociais do pensamento, então, logicamente, deve ser capaz de fornecer alguma explicação de suas próprias origens históricas

(EAGLETON, 1997, p. 100).

Os Cadernos do Cárcere nos apresentam, no seu contexto geral, uma releitura do conceito de ideologia elaborado por Marx, na medida em que a ideologia é um momento da construção da hegemonia enquanto luta de classes. As classes dominantes criam os mecanismos ideológicos para a conformação das massas a seu projeto social e político e quando estes instrumentos não funcionam recorre-se ao uso da força; ao mesmo tempo, os grupos subalternos, na luta pela transformação da sociedade ou pela conquista da hegemonia, precisam elaborar uma nova concepção de mundo, um novo modo de pensar que se traduza em novo modo de vida para toda a sociedade. 
No Caderno 7 temos uma distinção importante, que mostra o distanciamento de Gramsci em relação ao conceito de ideologia como mera aparência: Um erro no qual incorrem algumas leituras do conceito é dar “o nome de ideologia seja à superestrutura necessária de uma determinada estrutura, seja às elucubrações arbitrárias de determinados indivíduos" (Q. 7, p. 868).

O processo deste erro pode ser facilmente reconstruído: 1) identifica-se a ideologia como sendo distinta da estrutura e afirma-se que não são as ideologias que modificam a estrutura, mas sim vice versa; 2) afirma-se que uma determinada solução política é 'ideológica', ou seja, insuficiente para mudar a estrutura, enquanto crê poder modificá-la se afirma que é inútil, estupida, etc.; 3) passa-se a afirmar que toda ideologia é 'pura' aparência, inútil, estupida, etc. (Q. 7, p. 868).

Trata-se de "distinguir entre ideologias historicamente orgânicas, necessárias a uma determinada estrutura” e importantes para organizar massas humanas, das ideologias arbitrárias (Q. 7, p. 868). As ideologias historicamente orgânicas são necessárias e se articulam com as estruturas, formando o horizonte no qual os homens se relacionam, lutam e conquistam consciência de suas posições e, portanto, são importantes na luta de classes ${ }^{3}$. A análise dessas relações explicita-se no "conceito de 'bloco histórico'[...]", 4 no qual as "forças materiais são o conteúdo e as ideologias a forma", sendo que "a distinção entre conteúdo e forma é meramente didática", porque forças materiais e ideologia se articulam dialeticamente e não seriam historicamente concebíveis uma sem a outra (Q. 7, p. 869).

Nesse embate, a fragilidade dos grupos subalternos se evidencia no fato que sua concepção de mundo é fragmentada e contraditória, porque assimilada do exterior; como já acentuamos a propósito da hegemonia, sua história "é desagregada e episódica", sem unidade, de modo que a tendência para se organizar "é sempre rompida pela iniciativa dos grupos dominantes" que são unificados pela mediação do Estado (Q. 25, p. 2283). É o Estado que garante a unidade histórica dos grupos dominantes, de modo que os grupos

\footnotetext{
3 Ainda no Caderno 7 (p. 869) uma anotação recorda de memória algumas afirmações de Marx como "a solidez das crenças populares", ou o "modo de conceber tem a força das crenças populares", ou ainda que "uma persuasão popular tem geralmente a mesma energia de uma força material ou algo similar", a serem confirmadas nos escritos.

4 O conceito "bloco histórico", retomado de Sorel, se articula ao conceito "espirito de cisão" para explicitar as novas estratégias de luta revolucionária. Na crítica a Coce a propósito do significado de filosofia da praxis, Gramsci acentua que a "afirmação das Teses sobre Feuerbach, de que o 'educador deve ser educado', não coloca uma relação necessária de reação ativa do homem sobre a estrutura, afirmando a unidade do processo real? O conceito de 'bloco histórico' construído por Sorel, toma precisamente na íntegra esta unidade defendida pela filosofia da praxis (Q. 10, p. 1300).
} 
subalternos alcançarão unidade somente no momento em que tomarem o Estado. A ideologia assume aqui uma função prática de garantia do poder instituído ou de necessidade objetiva para conquistar a hegemonia.

Conforme Guido Liguori (2004, p. 147), para Gramsci a ideologia "é a representação da realidade própria de um grupo social”. Para o indivíduo a ideologia se apresenta como visão de mundo, que expressa a visão de mundo do grupo do qual ele faz parte. "Os sujeitos coletivos são definidos pelas ideologias", que são o "lugar de construção da subjetividade coletiva, mas também - de modo mais contraditório - da ideologia individual, no âmbito da luta hegemônica”.

A questão das formas da ideologia enquanto formação da consciência e transformação da realidade, que interagem entre si, é abordada por Gramsci no Caderno 10, quando se pergunta: “o que é o homem?” E responde que o homem é o que pode se tornar, ou seja, "é o processo de seus atos". E neste processo o homem produz sua individualidade e sua visão de mundo na medida em que interage com os outros e com o meio em que vive; pode-se dizer que "cada um transforma a si próprio, se modifica, na medida em que transforma e modifica todo o conjunto de relações do qual ele é o centro de ligação", de modo orgânico e complexo. $\mathrm{O}$ "homem não entra em relação com a natureza simplesmente pelo fato de ser ele próprio natureza, mas ativamente, por meio do trabalho e da técnica", entendida como instrumento e pensamento articulados; por meio do trabalho e da técnica o homem concretiza relações "ativas e conscientes" que transformam a natureza na medida em que modificam o modo de ser e de pensar do homem (Q. 10, p. 1345).

A partir desses pressupostos, salientamos outras passagens dos Cadernos nas quais esta questão se esclarece:

Pela própria concepção de mundo pertencemos sempre a um determinado grupo, precisamente aquele no qual se encontram todos os elementos sociais que compartilham um mesmo modo de pensar e de agir. Somos conformistas de algum conformismo somos sempre homens-massa ou homens-coletivos. A questão é esta: de que tipo histórico é o conformismo ou o homem-massa do qual fazemos parte? (Q. 11, p. 1376).

Deduz-se que: a) a ideologia forma o nosso modo de pensar pelo qual nos conformamos a um determinado grupo social; b) a consciência, portanto, não é uma coisa somente minha, individual, mas formação social; c) o pensamento não é neutro e que expressa o meu vínculo a um grupo social; d) importante saber a qual grupo pertencemos (ou de que lado da 
luta de classes nos encontramos). Segue-se que "não existe a filosofia em geral: existem diversas filosofias ou concepções de mundo e se faz sempre uma escolha entre elas". Cabe definir esta escolha (Q. 11, p. 1378). Outro momento:

Um grupo social que possui uma concepção própria do mundo, embora embrionária, que se manifesta na ação e, portanto, descontínua e ocasionalmente, ou seja, quando tal grupo se movimenta como um conjunto orgânico, toma de empréstimo de outro grupo, por razões de submissão e de subordinação intelectual, uma concepção que não é sua e a afirma por palavras e também acredita seguí-la, porque a segue em 'tempos normais', isto é, quando a conduta não é independente e autônoma, mas submissa e subordinada. E é por isso que não se pode separar a filosofia da política, mas pode-se, ao contrário, demonstrar que a escolha e a crítica a uma concepção de mundo são, também elas, fatos políticos (Q. 11, p. 1379).

A questão da ideologia (modo de pensar) elabora-se no movimento que se faz de colocação e superação das contradições enquanto parte da luta de classes e da conquista da hegemonia, ou seja, é essencialmente um fato político, de modo que se pode dizer que a verdadeira filosofia de cada um se encontra contida em sua posição política (Q. 11). Decorre daí que é necessário conhecer as correntes de pensamento na sua situação concreta, ou seja, na sua dimensão política e histórica.

No Caderno 4 (p. 442-443) Gramsci retoma o período da Restauração francesa para mostrar como se elabora o "historicismo" na realidade efetiva e no âmbito da ideologia: o movimento de restauração, enquanto "conserva", na realidade efetiva, "grande parte das conquistas do período precedente" reconhecendo o "predomínio da grande burguesia" e consolida seu programa "civil", ideologicamente desenvolve sua filosofia política a fim de justificar sua posição e criar um equilíbrio das forças em presença que consolide a hegemonia.

Alguns parágrafos do Caderno 4 foram retomados e ampliados no Caderno 11, na crítica ao Ensaio Popular de Bukharin. Nesse contexto, Gramsci acentua que a filosofia que assume essa dimensão histórica relacionando teoria e prática é o marxismo, que é também "uma teoria da historia, uma teoria da política e uma teoria da economia", conceitos que se articulam em "uma unidade orgânica". Como "filosofia o materialismo histórico afirma teoricamente que toda 'verdade' que se crê eterna e absoluta tem origens práticas” e representou um valor provisório. Mas ao próprio materialismo histórico ainda é difícil compreender essa situação no que se refere a si próprio. “Também o materialismo histórico tende a tornar-se uma 
ideologia no sentido pejorativo, ou seja, uma verdade absoluta e eterna”. Isso acontece quando o materialismo histórico se confunde com o materialismo vulgar, como no Ensaio de Bukharin (Q. 4, p. 465-466; Q. 11, p. 1402 e 1447-1448). Somente a luta de classes e a clareza da dimensão ideológica dessa luta pode abrir caminho para a construção de uma nova ordem social e política e para a compreensão do caráter histórico da verdade.

Na sua crítica ao pensamento de Croce e sua leitura da história, Gramsci acentua que esse intelectual não conseguiu distinguir "filosofia" de "ideologia" e, consequentemente, não soube reconhecer a "obra-prima política pela qual uma determinada classe consegue apresentar e fazer aceitar as condições de sua existência e de seu desenvolvimento de classe como princípio universal”. Nesse movimento de organização política, a classe adquire clareza de si e do conjunto de relações de força e consegue superar níveis de compreensão da realidade e de sua concepção de mundo, expressão de um "inteiro grupo social concebido em movimento" e que consegue superar "seus interesses atuais imediatos" para alcançar interesses gerais e mediados pela teoria (Q. 10, p. 1231). Trata-se de um movimento de passagem do particular para o universal com nuances diferentes para os grupos sociais e para os indivíduos que os constituem, nuances que traduzem níveis de acesso ao verdadeiro (concreto e real). Na medida em que se luta e, nos embates, se organiza uma vontade coletiva, muda-se o modo de pensar individual e a percepção (coletiva e individual) das contradições e dos conflitos.

Para Frosini (2013, p. 32), o ponto de partida de Gramsci para a leitura de Marx sobre a questão da ideologia é o texto Teses sobre Feuerbach, de 1845, com desdobramentos em A Miséria da Filosofia. Nestes escritos Gramsci identifica as bases de uma nova filosofia cujo conteúdo de verdade se encontra na articulação entre teoria e prática. Dessa perspectiva "de verdade como praxis e da consequente redefinição da ideologia como uma prática política da verdade" 5 , deve ser abordada a leitura de Gramsci do Prefácio de 1859 ou a interpretação gramsciana da definição de Marx das “[...]'formas ideológicas' como o lugar onde 'os homens se tornam conscientes' do 'conflito' social e 'o enfrentam'[...]”, tese que Gramsci toma como “gnosiológica e não psicológica ou moral” (Q. 4, p. 463).

A questão gnosiológica implícita na análise e interpretação gramsciana dos escritos de Marx tem o objetivo claro de acentuar que a verdade emerge

5 Grifo do autor. 
da mediação dialética entre estrutura e superestrutura, movimento no qual se produz a ideologia enquanto constitutiva das relações de hegemonia. Cabe entender como as ideias e categorias são criadas no movimento de formação e desenvolvimento das relações econômico-sociais e se tornam expressão de interesses de classe, de modo que um fato pode apresentar uma "dupla fenomenologia”, ou seja, expressar um progresso do conhecimento da realidade e tornar-se, ao mesmo tempo, um elemento de ideologia, na medida em que instrumentalizado para o desenvolvimento do modo de produção capitalista, com expressão na cultura em geral (Q. 4, p. 433) .

Desse contexto Frosini (2013, p. 33 - grifos do autor) explicita que, de Marx, "Gramsci extrai essa posição filosófica: entre verdade e ideologia não há diferença de status: a verdade não é um fato lógico, mas político”; é a "afirmação prática de uma força social capaz de absorver em si mesma os interesses das outras classes populares de forma subalterna”. É na prática, no confronto das forças em disputa, que se constrói a universalidade que, por surgir na prática, é sempre parcial e provisória porque "os processos de unificação de uma sociedade dividida em classes sempre deixam uma margem não absorvida, um resíduo de passividade e de violência”. A possibilidade de uma universalidade sem resíduos, a partir da supressão da divisão em classes, é o que propõe a filosofia da praxis, enquanto "teoria da relação entre história, conflito e ideologia", para construir, "pela primeira vez", uma "universalidade sem resíduos, que não deixe fora de si uma parte da sociedade, e que não integre o resto de forma subalterna, mas em um plano de igualdade absoluta”. A universalidade, portanto, é algo a ser construído no movimento "das lutas pela emancipação de si e das demais classes oprimidas".

Da perspectiva de Finelli, este movimento de construção se apresenta na "passagem de uma classe da subalternidade do seu próprio não-ser histórico ao seu próprio ser e existir como sujeito" histórico, o que acontece no processo de organização política e supõe a "produção de uma subjetividade coletiva, através da produção de uma ideologia que se caracterize, ao mesmo tempo, pelo maior grau possível de coerência" interna e "pela mais ampla

6 O tema dos princípios gnosiológicos da filosofia da praxis explicitados por Gramsci foi por nós abordado no artigo Hegemonia e educação: os princípios gnosiológicos do pensamento e da ação (SCHLESENER, 2014, p. 51-69). Os termos "desenvolvimento" e "progresso" são utilizados no sentido que lhes atribuía Pasolini $(1982,1995)$, que os entendia opostos e contraditórios: o desenvolvimento não implica necessariamente progresso e até o exclui, visto que se atribui ao modo de produção e reprodução capitalista a partir da produção e do consumo de mercadorias sedimentados na produção de necessidades supérfluas; o progresso, ao contrário, implica a geração de novas formas de vida a partir da satisfação das necessidades elementares e necessárias para a liberdade e a igualdade de todos. 
universalização" (FINELLI, 2003, p. 107-108, grifos do autor). De todo modo, o universal pode passar a existir apenas no processo de construção de uma nova ordem social e política que se caracterize pela produção da igualdade coletiva.

Chatelet (1972, p. 202) acentua que, a partir da dimensão empírica que caracteriza a existência humana, pode-se distinguir "o que é fundamental" daquilo "que é histórico": existem condições objetivas que precisam ser reconhecidas como verdades, como, por exemplo, tem-se que reconhecer como verdade objetiva o fato que existem necessidades cuja satisfação é fundamental para a reprodução da vida humana; que a natureza humana se caracteriza por sua materialidade, a ser transformada pelo trabalho; a exploração da força de trabalho e sua redução a mercadoria, base da alienação, é um fato histórico a ser enfrentado. Marx procurou mostrar as contradições que se apresentam entre um universal legitimador de uma ordem social e política que tem uma dimensão histórica e que, portanto, é provisória e pode ser subvertida.

Gramsci reinterpreta Marx a propósito da questão da ideologia na crítica ao pensamento de Croce e às contradições nas quais este cai na sua leitura de Marx; neste contexto, define: "as ideologias são construções práticas, são instrumentos de direção política”. Para Marx, longe de serem ilusões e aparências, como entende Croce, as ideologias "são uma realidade objetiva e operante, mas não são a mola da história", porque "não são as ideologias que criam a realidade social, mas é a realidade social, na sua estrutura produtiva, que cria as ideologias" (Q. 4, p. 436).

$\mathrm{Na}$ interpretação de Liguori (2007, p. 137), esta expressão parece similar ao que diz Marx em A Ideologia Alemã: "Não é a consciência que determina a vida, mas a vida que determina a consciência”, embora não se saiba se Gramsci teve acesso ao conteúdo desse escrito, cuja primeira parte, Feuerbach, foi publicada em russo em 1924 e em alemão em $1926^{7}$.

Gramsci acentua que, para Marx, as ideologias "são uma realidade objetiva e operante, mas não são a mola da história”, no sentido que "não são as ideologias que criam a realidade social”, mas é ela que, "na sua estrutura produtiva, cria as ideologias". Também a teoria de Marx faz parte da superestrutura, com uma diferença fundamental em relação às outras ideologias: a sua teoria visa a "fazer 'tomar consciência' a um determinado

7 Cfr. Cesare Luporini, em publicação de 1967. Citamos a partir das informações de Guido Liguori. 
grupo social das próprias tarefas, da própria força, do próprio devir histórico”, ou seja, tem um teor de verdade primeiro, porque supera tanto as correntes idealistas quanto as leituras mecanicistas sedimentadas no materialismo filosófico vulgar e, superando-as, alcança um nível superior de conhecimento da realidade na mediação dialética entre teoria e prática; segundo, porque visa a esclarecer os subalternos dos grilhões invisíveis que os prendem com o objetivo de orientar as suas lutas. Para os grupos sociais dominantes, ao contrário, as ideologias servem como "instrumentos práticos de domínio político sobre o restante da sociedade”, mesmo estando essas ideologias em contradição com a realidade efetiva, ou seja, tenham o objetivo de obnubilar a realidade, esconder elos de submissão que existem na prática (Q. 4, p. 436-437).

Esse fragmento do Caderno 4 é retomado e redefinido no Caderno 10, onde a crítica à ideia croceana de que a ideologia é ilusão e aparência, Gramsci explica: as ideologias não são ilusões, nem aparências, "são construções práticas, instrumentos de direção política, ou seja, poder-se-ia dizer que as ideologias são meras ilusões para os governados", como um engano sofrido, enquanto para os governantes "são um engano voluntário e consciente" (Q. 10, p. 1319).

As ideologias são tudo menos arbitrárias: são fatos históricos reais que é necessário combater e desvelar na sua natureza de instrumentos de domínio, não por razões de moralidade, mas por razões de luta política: para tornar intelectualmente independentes os governados dos governantes, para destruir uma hegemonia e criar uma outra, como momento necessário de subversão da praxis (Q. 10, p. 1319).

Existe "uma diferença fundamental entre a filosofia da praxis e as outras filosofias": As ideologias dominantes são "criações inorgânicas porque contraditórias, criadas para conciliar interesses opostos e contraditórios" ocultando as contradições reais; porém as contradições tendem a aflorar e, com isso, a evidenciar os seus limites. A filosofia da praxis, ao contrário, "não tende a resolver pacificamente as contradições existentes na história e na sociedade, pelo contrário, é a mesma teoria de tais contradições; não é instrumento de governo de grupos dominantes para obter o consenso e exercer a hegemonia sobre as classes subalternas"; a filosofia da praxis "é a expressão destas classes subalternas que querem se educar a si próprias na arte de governo e que tem interesse em conhecer toda a verdade", mesmo as desagradáveis, a fim de evitar novos enganos (Q. 10, p. 1320). 
Aqui se explicita tanto os significados diversos de ideologia quanto os princípios gnosiológicos que fundamentam a filosofia da praxis que, enquanto teoria das contradições, é a expressão da verdade das relações de dominação que mascaram os conflitos sociais na sociedade capitalista e a dialética do próprio devir histórico, no qual se inclui enquanto teoria reconhecendo seus limites.

Essas formulações se ampliam se relacionadas ao Caderno 13, na leitura gramsciana de Maquiavel: o "caráter fundamental de $O$ Príncipe é o de não ser um tratado sistemático, mas um livro 'vivo'[...]”, ou seja, um livro que alia a teoria à prática e pelo qual Maquiavel explicita o "processo de formação de uma determinada vontade coletiva para um determinado fim político". Dessa perspectiva, o livro "poderia ser estudado como um exemplo histórico do 'mito' soreliano, ou seja, de uma ideologia política”, que atua sobre a "fantasia concreta de um povo disperso e pulverizado para despertar e organizar sua vontade coletiva” (Q. 13, p. 1555-1556). E Gramsci explicita os limites da noção de mito em Sorel, para acentuar os caminhos possíveis, a partir da análise da história italiana, para a formação de uma vontade coletiva nacional-popular.

O mito se apresenta não como utopia distante, mas como "uma criação da fantasia concreta", que serve para organizar uma população dispersa e desagregada em torno de um projeto comum. Os elementos míticos se expressam na convocação para a ação de um Príncipe efetivo, que Maquiavel apresenta no último capitulo do seu livro. Um líder verdadeiro que organize o movimento de fundação de um novo Estado. Esse elemento permite a Gramsci acentuar que o moderno príncipe deveria ser o Partido Político, evidentemente não um partido eleitoreiro como os que se organizam nos limites do Estado burguês, mas um partido que represente um novo projeto social e político. A esse ponto Gramsci aproxima o significado político da obra de Maquiavel ao Manifesto do Partido Comunista de Marx e Engels, mostrando que ambos, em momentos diferentes da história moderna, escreveram para classes revolucionárias que visavam a subverter a praxis a partir de seus projetos inovadores (Q. 13, p. 1556-1558).

A crítica ao mito soreliano se estende a todas as teorias que não levam até as últimas consequências a formação da vontade coletiva e a ação revolucionária por seus limites teóricos ou, ainda, práticos, tendo como pano de fundo a relação dialética efetiva entre teoria e prática ${ }^{8}$ : um projeto

8 Maquiavel, conforme Gramsci, escreveu para a classe revolucionaria de sua época, mas essa parece que não entendeu a mensagem, ou seja, não havia ainda, na prática, as condições necessárias para esse 
político que mobilize as massas não pode deixá-las no meio do caminho, sem sair de sua fase elementar e primitiva; precisa superar todos os entraves e encantamentos, tanto do mecanicismo ou do materialismo vulgar quanto do idealismo, além de considerar que a ação efetiva exige destruir para construir o novo, ou seja, implica sempre recorrer a alguma forma de violência (Q. 13, p. 1557). Uma vontade coletiva deixada na sua fase elementar e corporativa acaba se fragmentando em tendências que podem perfeitamente ser cooptadas pelas classes dominantes ou se dissolvendo enquanto projeto político, ou seja, Gramsci acentua a necessidade de uma racionalidade efetiva que se proponha dirigir em vista a um projeto político alternativo. Este é o sentido da luta9 ${ }^{9}$

O caráter inovador do projeto a ser levado avante pelo moderno príncipe consiste em "criar uma vontade coletiva ex novo, original, orientada para finalidades concretas e racionais, mas de uma concreticidade e racionalidade" que ainda não ocorreram como "experiência histórica efetiva e universalmente conhecida" (Q. 13, p. 1558).

Gramsci acentua aqui a natureza de uma revolução efetiva, que implica a originalidade da vontade coletiva enquanto consciência de sua força inovadora e de sua necessidade histórica, entendendo-se "protagonista de um drama histórico real e efetivo”. Um movimento de caráter jacobino, no sentido amplo que esta noção teve historicamente e no significado conceitual no qual deve ser entendida. Quando Gramsci acentua que se trata de um movimento que subverte todo o sistema de relações econômicas, sociais, políticas e ideológicas de modo novo e original está falando em uma verdadeira revolução a partir da organização das classes subalternas, na linha da política desenvolvida pelo L’Ordine Nuovo. Para tanto, as classes subalternas precisam entender o movimento das estruturas, as "razões dos sucessivos

entendimento, principalmente na Itália. Maquiavel foi compreendido pela primeira vez por Rousseau e Gramsci só pode fazer esta leitura depois de Marx e da consolidação da revolução burguesa na Europa, ou seja, depois do processo concluído.

9 “A ordem e a desordem são as duas palavras que aparecem com mais frequência nas polêmicas de caráter político. [...] A palavra ordem tem um poder taumatúrgico: a conservação das instituições políticas é, em grande parte, confiada a esse poder. A ordem presente apresenta-se como algo de harmonicamente coordenado, de estavelmente coordenado; e a multidão dos cidadãos hesita e se amedronta ante a incerteza daquilo que uma mudança radical poderia trazer. O senso comum, o estúpido senso comum geralmente prega que é melhor um ovo hoje do que uma galinha amanhã. E o senso comum é um terrível escravizador dos espíritos. Tanto mais quando para ter a galinha é necessário romper a casca do ovo. Forma-se na fantasia a imagem de uma coisa de violentamente lacerada; não se vê a nova ordem possível, melhor organizada e mais vital que a velha ordem, porque ao dualismo se contrapõe a unidade, à imobilidade estática da inércia, a dinâmica da vida movendo-se autonomamente. Vê-se somente a laceração violenta e a alma apavorada volta atrás com medo de perder tudo, de ter diante de si o caos, a desordem inelutável" (GRAMSCI, A. apud SCHLESENER, A. P. 2015, p. 197). 
fracassos das tentativas de criar uma vontade coletiva nacional-popular", assim como aconteceu com a burguesia comunal, a fim de enfrentar os conflitos na luta pela hegemonia (Q. 13, p. 1559).

O Caderno 13 é rico em análises a respeito das relações de forças, das dimensões que a luta de classes assume no cotidiano, dos encaminhamentos políticos no sentido da emancipação das classes subalternas e, principalmente, as formas que assume a ideologia no âmbito deste embate. Retomamos essas observações a propósito da educação e dos mecanismos ideológicos de formação da subjetividade porque entendemos, como acentua Dias (2012, p. 318), que o "domínio de uma classe (e de seu bloco de poder) determina o que pensar, o que estudar e até mesmo o que e como amar”. Ou seja, a ideologia assume uma dimensão desmesurada na medida em que serve para consolidar relações de domínio e a educação, em geral, funciona como o meio para a realização desses objetivos.

\section{A ideologia e a formação da subjetividade}

A verdade pode ser mortal e a mentira eterna? Tudo me leva a crer (BRECHT, 1982, p. 52).

Falar de ideologia implica abordar também a questão da educação, visto que é por meio da educação que se formam as concepções de mundo e a própria subjetividade. Da perspectiva gramsciana a educação se faz ao longo da vida e o indivíduo não é um ser isolado, mas, ao contrário, sua individualidade se produz na medida de seu envolvimento social. Toda a vida, por sua vez, tem uma dimensão política e histórica. A educação, para Gramsci, tem uma dimensão política revolucionária, visto que, para as classes subalternas, trata-se sempre de apropriar-se do conhecimento como consciência crítica, percepção das contradições e sua superação dialética.

Da perspectiva da sociedade capitalista e da hegemonia burguesa, a educação é um instrumento de adaptação ao contexto econômico e social que se objetiva consolidar e manter; educar é formar para a vida em sociedade, é conformar a projetos, é realizar uma ideia de civilização. Nesse contexto, a educação faz parte da própria natureza do Estado e de seus objetivos, visa uma determinada ordem social e determinadas relações de hegemonia, que se instauram e se renovam como correlação de forças.

Do ponto de vista das classes trabalhadoras, a educação pode ser um processo de adaptação à ordem instituída, mas pode também ser forma de 
reconhecimento dos conflitos sociais e de construção de uma identidade de classe. Significa organizar-se, interagir uns com os outros a fim de criar uma vontade coletiva, conhecer o conjunto de relações tanto em um dado momento histórico quanto em seu movimento de formação e transformação para tornarem-se ativos e capazes de organizar movimentos para mudanças efetivas.

De ambas as perspectivas, a questão da educação implica compreender as dimensões da luta de classes, nas formas mais atualizadas de participação em um horizonte ideológico que consolida a ordem instituída. A luta por novas relações de hegemonia produz-se como experiência de uma nova educação, que se apresenta para Gramsci como a formação de um novo homem que, por seu conhecimento crítico e ativo da realidade econômica e social em que se insere, é capaz de tomar nas mãos o seu destino.

A partir desses pressupostos cabe entender a questão da formação da subjetividade, não a partir do indivíduo isolado, mas a partir das formas como este indivíduo interage com o meio social e natural pela mediação do trabalho e como se torna conformista de algum conformismo. Cabe esclarecer que este conceito, o conformismo, é utilizado por Gramsci com um significado diverso daquele comumente usado na atualidade. No Caderno 13, parágrafo 7, Gramsci explicita esse conceito, implicitamente voltado a pensar a educação em uma nova sociedade:

Tarefa educativa e formativa do Estado, cujo fim é sempre criar novos e mais elevados tipos de civilização, de adequar a 'civilização' e a moralidade das mais amplas massas populares às necessidades do contínuo desenvolvimento do aparelho econômico de produção e, portanto, de elaborar também fisicamente tipos novos de humanidade. Mas como cada indivíduo singular conseguirá incorporar-se no homem coletivo e como ocorrerá a pressão educativa sobre cada um para obter seu consenso e a sua colaboração, transformando em 'liberdade' a necessidade e a coerção? Questão do ‘direito', cujo conceito deverá ser ampliado [...] (Q. 13, p. 1565-6)

Para Gramsci, o conceito “conformismo" pode ser tido como sinônimo de sociabilidade, ou seja, expressa uma situação de pertencimento a um determinado grupo social com o qual compartilhamos uma concepção de mundo, elementos da vida social que expressam um comportamento, um mesmo modo de pensar e de agir. Sempre "se é conformista de algum conformismo, sempre se é homens-massa ou homens-coletivos" e adaptar-se implica sofrer algum tipo de coerção. A questão é saber de que tipo de conformismo fazemos parte. "Quando a concepção de mundo não é crítica e coerente, mas ocasional e desagregada significa que pertencemos simultaneamente a 
uma multiplicidade de homens-massa" e a nossa personalidade se compõe dos elementos mais arcaicos combinados com elementos da ciência mais moderna. Qualquer projeto político alternativo implica fazer a crítica a esse modo de pensar desagregado e contraditório para formar uma concepção de mundo coerente e unitária (Q. 11, p. 1376).

Cabe acentuar que o homem é definido por aquilo que faz e toda ação exige um certo tipo de formação e de disciplina, processo que faz parte da educação. No Caderno dedicado ao americanismo e fordismo, Gramsci acentua que o processo civilizatório exigiu do homem esforços inauditos para se adaptar ao trabalho e a todas as exigências colocadas pela superação das necessidades, principalmente a partir do industrialismo, cuja história se apresenta como uma contínua luta de superação e aperfeiçoamento, muitas vezes doloroso e sangrento, na criação de formas sempre mais complexas de vida coletiva (Q. 22, p. 2160).

Gramsci, exceto a exploração do trabalho, não considera esse esforço de adaptação uma coisa negativa, mas entende como parte do processo de criação do homem, acrescentando que todo esforço físico, inclusive o mais mecânico e automatizado, em gestos simples e repetidos, exige um mínimo de atividade intelectual criativa. "Os industriais americanos entenderam muito bem esta dialética contida nos novos métodos industriais". Entenderam que "gorila amestrado" é uma frase, uma metáfora, porque o operário permanece homem e, portanto, pensa; e "não apenas pensa, mas a insatisfação no trabalho" pode levar o trabalhador a uma posição "não conformista” (Q. 22, p. 2170-2171).

Nesse contexto, a posição de Gramsci difere da de Marx quanto à formação da individualidade: Marx via na luta por uma nova ordem social e política a possibilidade de o homem realizar sua individualidade a partir da satisfação de seus desejos e capacidades individuais (MARX, ENGELS, 1976); Gramsci explicita e amplia esta noção ao articular o desenvolvimento individual com a vida coletiva e os interesses da sociedade da qual se faz parte.

A questão se apresenta no Caderno 13, a propósito do que significa "homem-coletivo" ou "conformismo social”, abordada como uma questão fundamental de educação, que implica o compromisso formativo do Estado no sentido de elevar as massas populares a um determinado nível de "civilização", adequando essas massas "às necessidades do contínuo desenvolvimento do aparato econômico de produção" elaborando "também fisicamente tipos novos de humanidade". Trata-se, para Gramsci, de explicitar como "cada 
indivíduo singular conseguirá incorporar-se no homem coletivo e como se fará a pressão educativa sobre os indivíduos para obter seu consenso e colaboração" a fim de transformar em "liberdade" a necessidade e a coerção. Gramsci atribui uma função importante ao direito como regulador desse processo e a necessidade de reformular as normas jurídicas em uma nova ordem social e política (Q. 13, p. 1566).

Deste contexto pode-se concluir que todo processo educativo implica alguma forma de coerção e de convencimento e que Gramsci entende que isso é necessário para adequar os indivíduos aos interesses do sistema produtivo e da sociedade em geral. Neste contexto, a escola é uma das instituições educativas que visa a cumprir esta função. A questão de fundo é que a individualidade é construída na vida coletiva, nas formas como se produz o "conformismo", que Gramsci classifica como podendo ser "imposto" ou "proposto", ou seja, aceito voluntariamente e, então, deixaria de ser realmente um "conformismo" (Q. 9, p. 1110).

Vemos neste fragmento que o conceito "conformismo" apresenta um aspecto negativo que se refere especificamente ao seu caráter impositivo. Gramsci procura mostrar a diferença entre individualismo e individualidade, acentuando que esta se elabora a partir de uma consciência crítica:

Que se lute para destruir um conformismo autoritário, que se tornou restrito e incômodo e atravessando uma fase de desenvolvimento da individualidade e personalidade crítica se alcance o homem-coletivo é uma concepção dialética difícil de compreender por meio da mentalidade esquemática e abstrata (Q. 9, p. 1111).

fundo, a individualidade se forma no contexto das relações sociais, no movimento histórico de produção e superação das contradições, entre as quais as mais variadas formas de coerção, desde a mais brutal, que passa pela violência física e adaptação do corpo, até a mais sutil, que envolve o convencimento por meio de mecanismos ideológicos. Cabe reconhecer no processo de conformação do indivíduo à sociedade o movimento educativo de superação dos grilhões ideológicos que o submetem; a formação de uma individualidade crítica e autônoma depende da compreensão do processo de interação social no qual o indivíduo se insere e se efetiva a educação.

Muitas são as ideologias que limitam a liberdade do homem e impedem que tome nas mãos o seu destino, entre elas as religiões de todos os matizes (ópio do povo, como dizia Marx), o jogo de azar ou as loterias (ópio da miséria, como acentua Gramsci, formas de fazer o pobre pagar imposto, além daquele que é retirado do seu salário), além de todas as outras crenças que 
impedem um pensamento autônomo. Educar implica atuar na formação da subjetividade da criança, tarefa delicada porque o limiar entre a disciplina necessária para tal formação e a coerção é muito frágil.

Embora Gramsci acentue as dificuldades de uma visão dialética do assunto, temos que concordar com Bodei (1999), que tanto a noção de disciplina quanto a de coerção são ambíguas e não estabelecem muito bem os limites entre o que é opção autônoma e o que é constrangimento, até porque o próprio Gramsci acentuava a propósito da censura, que a repressão constante se assimila e se interioriza, virando controle interno ${ }^{10}$. A amplitude de significados que assumem esses conceitos torna difícil defender uma disciplina, que pode assumir tanto a forma de uma imposição autoritária quanto se diluir na lenta formação do comportamento a partir da assimilação ou interiorização imperceptível da repressão.

\section{Elevar as massas ao maior nível intelectual: a importância da educação}

O poder distorce a visão dos céus impondo seus pesados telescópios sobre certas áreas, de modo que sua importância se amplia, obstruindo outras de forma avassaladora, que ficam

completamente invisíveis (BUCK-MORSS, 200o, p. 51).

A reversibilidade entre ser e conhecer Gramsci a aponta como uma das qualidades da filosofia da praxis. Um processo de formação difícil e complicado que se faz em seguir o movimento contraditório da vida, tanto na sua materialidade quanto na nossa imaginação. A filosofia da praxis é dialética, isso é, não se apresenta como um sistema explicativo e abstrato, mas como um pensamento aberto, histórico, inacabado e sempre recomeçado, que enfrenta o paradoxal, o ambíguo e o contraditório, como solo fértil para novas reflexões. Nesse contexto, as categorias fundamentais para a compreensão do movimento real deixam de ser a pura consciência de si e o pensamento voltado sobre si mesmo, mas a contradição e as formas que esta assume no processo de construção das condições materiais de existência. Esse é também um movimento de reconhecimento e superação das ideologias.

Se tomarmos a ideologia como parte da construção das relações de hegemonia, podemos afirmar a importância que assumem os intelectuais dos grupos dominantes no contexto das relações políticas, assim como o 
processo de educação escolar. A fim de contextualizar a questão, retomamos os pressupostos já colocados no primeiro capítulo: a sustentação dos escritos de Gramsci são as relações de força vigentes no seu momento histórico e, embora analisadas em confinamento, servem de base para explicitar a divisão da sociedade em classes bem como as características específicas dessa luta no momento de ascensão das forças fascistas. A análise dos conflitos gerados pelo antagonismo de classes e dos mecanismos ideológicos para a conservação da hegemonia permitem entender a relevância da educação para as classes trabalhadoras, tanto nas instituições regulares (como a escola) quanto nas organizações nascidas da luta por uma nova sociabilidade (associações de cultura, jornais, grupos de estudos, etc.).

Uma das bases para compreender os desdobramentos desse processo é o Caderno 13, quando Gramsci identifica nos escritos de Maquiavel as bases para entender a questão da hegemonia enquanto exercício do poder pelo equilíbrio entre coerção e consentimento. Gramsci acentua que Maquiavel, indiretamente, abordou a questão da ideologia ao divulgar um "princípio elementar da arte política que é o de que certas coisas se fazem, mas não se dizem”, ou seja, Maquiavel anunciou aos quatro ventos as práticas de poder que podem ser realizadas somente se não forem conhecidas pelas massas (Q. 13, p. 1675).

Ao tornar públicas tais práticas, Maquiavel as desmistifica e, consequentemente, as inviabiliza; nesta senda, esta pode ser uma das semelhanças da teoria política de Maquiavel com a filosofia da praxis: revelar a verdade a quem não sabe, a fim de possibilitar a sua emancipação política. Isso se torna possível na medida em que a base de análise é a realidade efetiva ou as conjunturas e estruturas em determinado momento histórico.

Gramsci faz outras aproximações entre Maquiavel e Marx, como mostrar que as duas teorias são revolucionárias, cada uma dirigida para a classe social que tem condições de fazer a revolução; ambas as teorias tem como base a desigualdade social que se constitui na origem da divisão entre dirigentes e dirigidos ou os que ordenam e projetam a sociedade e os que obedecem e se calam ou são calados; ambos os autores mostram que, no movimento de correlação de forças, as relações de poder podem inibir ou incentivar um comportamento, ou seja, são relações educativas em processo.

Desta perspectiva, ou seja, partindo-se do antagonismo de classes enquanto correlações de forças, defesa e conservação ou destruição e renovação da estrutura econômica e social (Q. 13, p. 1564), a educação escolar 
cumpre a função de adaptar os indivíduos aos interesses do mercado de trabalho e do sistema produtivo, mantendo a hierarquia dentre dirigentes e dirigidos; para as classes trabalhadoras, a escola é importante porque fornece os códigos necessários para a leitura das relações sociais e, como a sociedade é permeada por contradições, a educação escolar pode ser também um dos meios de formação para a emancipação política.

A questão da educação perpassa a teoria política na medida em que as relações de hegemonia são relações educativas e o Estado se apresenta, para Gramsci, como o principal educador, seguido pelo ambiente, que também educa, envolvendo todas as instituições sociais, desde a família, as igrejas, os meios de comunicação de massa, aparato jurídico, ou seja, todas as instâncias socais que formam o indivíduo ao longo de sua vida. Nessa estrutura social educadora elaboram-se e consolidam-se as ideologias no modo de ser e nas concepções de mundo que orientam e condicionam a vida de cada um.

A partir desses pressupostos, a perspectiva de Gramsci, ao analisar uma determinada situação, é saber em que medida ela serve para a formação emancipadora das classes populares ou para a conservação das relações de dominação e submissão. Porque a ideologia submete sem que o indivíduo ou o grupo se apercebam. A assimilação continuada de informações apresentadas como verdades absolutas e universais são fundamentais para a conservação de uma hegemonia alterando de modo decisivo a forma e o conteúdo da luta de classes.

Nessa sociedade marcada pela desigualdade social gerada pela exploração do trabalho não existem verdades absolutas e válidas indiferentemente para todos. O que é verdadeiro para os grupos dominantes não o é para os grupos dominados ou subalternos, embora eles a tomem como sua verdade; assim também acontece com algumas palavras abstratas e descontextualizadas que servem apenas para fortalecer os grilhões invisíveis que se consolidam como ideologia. Uma palavra exemplar é "paz”, que o senso comum repete como uma realidade que aspira sem se dar conta que, na estrutura contraditória e antagônica desta sociedade, a paz é uma miragem.

A filosofia da praxis se propõe analisar a realidade para "organizar racionalmente aquilo que os agentes históricos desta realidade sentem confusa e instintivamente". Para tanto, colocou-se como tarefas "combater as ideologias modernas na sua forma mais refinada e esclarecer as massas populares, cuja cultura era medieval” (Q. 4, p. 422). Ou seja, Gramsci acentua 
que uma das tarefas do marxismo é elevar o nível cultural das massas populares, processo essencialmente educativo que consiste em mostrar às classes trabalhadoras a necessidade política de se reconhecerem no movimento contraditório de construção da sociedade e de refletirem sobre suas lutas, seus sonhos e seus projetos. A educação, nesse contexto, se articula com o conceito de hegemonia, que tem como pressuposto a luta de classes e o espírito de cisão, ou seja, a formação de uma consciência crítica capaz de ler os detalhes do real e de promover uma reforma intelectual e moral como parte de um processo revolucionário.

Reconhecer-se no movimento contraditório das relações sociais significa entender o processo de dominação alicerçado na estrutura do modo de produção para tomar novas dimensões no modo de pensar, na medida em que as classes dominantes se apropriam do passado cultural apresentando-o numa versão homogênea e sem conflitos, para consolidar seu poder. Nesse contexto, elevar as massas ao maior nível intelectual significa entender que as novas características da luta de classes implicam enfrentar o dominador no mesmo terreno, ou seja, elaborar uma consciência crítica e a sua própria concepção de mundo a fim de reinterpretar todo o passado cultural a partir de uma perspectiva mais abrangente da realidade. Embora a abordagem suponha a formação de uma identidade de classe, o conhecimento a ser produzido da perspectiva da filosofia da praxis não é um conhecimento a ser guardado e utilizado pela própria classe para uma nova forma de dominação, mas precisa ser coletivizado, o que significa torná-lo fonte de libertação para toda a humanidade.

Essa questão torna-se fundamental, porque a fragilidade dos vencidos se determina pelo fato de que não possuem clareza de sua própria história, porque esta não tem uma narrativa organizada que evidencie suas práticas e interesses de classe. E essa formação se torna mais importante e urgente na medida em que o conhecimento se transforma em instrumento de poder e de aprofundamento das desigualdades sociais. Para as classes trabalhadoras ter acesso ao conhecimento historicamente produzido significa ter acesso aos instrumentos de libertação da dominação capitalista, sem os quais torna-se muito difícil superar as limitações impostas e efetivar a construção de uma nova ordem social e política.

Como acentua Dias (2012, p. 123), "quando os intelectuais burgueses pensaram sua passagem ao comando das sociedades europeias eles o fizeram do ponto de vista da modernidade". Como tal, pensavam em implementar direitos, a "liberdade de saber, pensar, expressar novas convicções" e a 
ciência como "possibilidade de diminuir o sacrifício físico na produção e criar a igualdade na política, como libertadora". O que realizaram efetivamente foi uma modernidade de acordo com seus limites, como um novo modo de vida, mas determinado por interesses de classe.

O capitalismo, por suas próprias necessidades e limitações, "afirmou a liberdade abstrata dos indivíduos-mônadas" e a liberdade efetiva dos proprietários. Os ideais revolucionários eram "incompatíveis com a produção, só cabendo aí a 'liberdade capitalista', a da extração legalizada do mais-valor" (DIAS, 2012, p. 130-131). Elevar as massas ao maior nível intelectual significa proporcionar-lhes as condições de romper com esse processo repetitivo de dominação e, para tanto, torna-se necessário redefinir o processo educativo.

Esse tema implica explicitar a questão da linguagem na sua dimensão política; se a hegemonia se produz e se conserva como equilíbrio entre coerção e consenso e este se forma no cotidiano imediato pela formação de um modo de pensar homogêneo, evidente que a linguagem se torna o meio de veiculação da ideologia e das ideias dominantes. E novamente a importância dos intelectuais se evidencia, principalmente quando se constituem em casta que controla e veicula o pensamento. A questão a ser enfrentada nesse contexto é mostrar que, na história, o controle da palavra sempre pertenceu aos dominantes e na sociedade moderna, mais do que nunca, esse poder se multiplicou com a inserção das novas tecnologias de comunicação e, consequentemente, romper grilhões e vencer as lutas políticas implica dominar a linguagem e formular um pensamento autônomo para enfrentar o dominador no seu terreno. Esse tema desenvolveremos a seguir. 